\title{
Chemical composition and antioxidant activity of essential oil of leaves and flowers of Alternanthera sessilis red from Sabah
}

\author{
Mohammad Shaheen Khan ${ }^{1 *}$, Samina Khan Yusufzai ${ }^{2}$, Lim Phaik Kaun ${ }^{1}$, Muhammad Dawood Shah ${ }^{3}$, Rubia Idris ${ }^{1}$ \\ ${ }^{1}$ Industrial Chemistry Programme, Faculty of Science and Natural Resources, University Malaysia Sabah, 88400 Sabah, Malaysia. ${ }^{2}$ School of Chemical \\ Sciences, Universiti Sains Malaysia,11800 Pulau Penang. ${ }^{3}$ Biotechnology Research Institute, Universiti Malaysia Sabah, Jalan UMS, Sabah, Malaysia.
}

\begin{tabular}{l}
\hline ARTICLE INFO \\
\hline Article history: \\
Received on: $11 / 04 / 2016$ \\
Revised on: $19 / 05 / 2016$ \\
Accepted on: $07 / 07 / 2016$ \\
Available online: $28 / 12 / 2016$ \\
\hline
\end{tabular}

Key words:

Alternanthera sessilis, Antioxidant Activity,BHT, 1,1-Diphenyl-2picrylhydrazyl, Essential Oil, GC-MS analysis.

\begin{abstract}
In the present study, chemical composition and antioxidant activity of essential oil from the aerial parts of Alternanthera sessilis red has been investigated. The chemical composition of essential oil of A. sessilis red was determined by GC-MS analysis. Determination of antioxidant nature of A. sessilis red was carried out by 1,1diphenyl-2-picrylhydrazyl (DPPH) radical scavenging method using butylated hydroxytoulene (BHT)as the positive control. The major components of essential oil of leaves, as analyzed by the GC-MS were found to be 1,1,1,5,5,5-hexamethyl-3,3-bis[trimethylsilyl)oxy]trisiloxane $\quad(15.43 \%), \quad \mathrm{S}, \mathrm{S}$-dioxide $\quad$ trans-2-methyl-4- $\mathrm{N}$ pentylthiane $(11.27 \%)$, didodecylphthalate $(10.62 \%)$ and tetrahydro-2,5-dimethoxy furan $(10.01 \%)$. However, the major components of essential oil of flower were 1,1,1,5,5,5-hexamethyl-3,3bis[trimethylsilyl)oxy]trisiloxane $\quad(17.76 \%), \quad$ trans-4-ethyl-5-octyl-2,2-bis(trifluromethyl)-1,3-dioxolane $(11.12 \%)$ and tetrahydro-2,5-dimethoxy furan $(9.10 \%)$.
\end{abstract}

\section{INTRODUCTION}

Alternanthera sessilis red or red carpet weed belongs to the family Amaranthaceae which known as a medicinal plant in Asia (Vinodh and Kumar, 2014). In Malaysia it is commonly known as keremak, pudohrumputaoh and serapat depending upon the local areas. Young shoots and leaves of this weed are harvested as vegetables. It also serves as good ground cover and fodder. According to CRC world dictionary of Medicinal and poisonous plants $A$. sessilis has reddish-purple stem at base, papery leaves with white bracts and pink whitish perianth and inflorescence bracts (Quattrocchi, 2012). A. sessilis grows under variety of soil and climatic conditions. Wet soil condition is found to be the best for its growth, but it is habitant for marshy areas and wetlands (Vennila and Nivetha, 2015). It is a weed of rice in tropical areas and a pest of sugarcane and bananas (Das and Borua, 2014). Several therapeutic benefits of Alternanthera

\footnotetext{
* Corresponding Author
}

Email: shaheenchem@gmail.com sessilis has been investigated which includes anti diabetic, antiinflammatory, cytotoxic effect toward pancreatic cancer lines and free radical scavenging activity (Tan and Kim, 2013). Previous biological analysis of $A$. sessilis revealed the presence of different phytochemcial compounds from its various organic extracts. Triterpenoids, phytosterols and glycosides were found to be the main phytoconstituents for anti-diabetic activity of this weed (Das et al., 2015). Nayak et al. (2010) has reported its antipyretic activities. The aqueous alcoholic extract of the entire plant was found to have the ability to modulate the histamine system and act as a smooth muscles relaxant.

An ethereal extract was found to possess anti-ulcerative property (Das and Borua, 2014). The plant was also found to be rich in antioxidant carotene (Patel et al., 2015). The above therapeutic studies have been reported in the different organic extracts. Therefore, the aim of this study was to determine the chemical composition of the essential oil of its aerial parts and investigate their antioxidant activity. At the best of our knowledge there are no published studies that have reported these results for the essential oil of $A$. sessilis. 
Most of the medicinal plants which are mean to cure daily ailments have been found to possess antioxidant properties (Hossain and Shah, 2015). Natural antioxidant from medicinal plants sources are always popular in the food industries. They can be added to variety of foods for the prevention of oxidation via inhibiting the initiation of the radical chain reaction and also propagation steps resulting in the termination of the oxidation reaction processes (Nimse and Pal, 2015). The popularity of natural antioxidants is growing based on the fact that few synthetic antioxidants such as butylated hydroxyanisole (BHA) and BHT are now suspected to be harmful to human health as they confer some degree of carcinogenicity.

\section{MATERIALS AND METHODS}

\section{Plant material}

Alternanthera sessilis red was collected at flowering stage from Orchard De Villa which is located at Luyang Kota Kinabalu, Sabah, Malaysia (Fig. 1). The botanical identification and confirmation was achieved by Borneo Herbarium, Universiti Malaysia Sabah where a voucher specimen 00001-LPK/LYY was deposited in the herbarium.

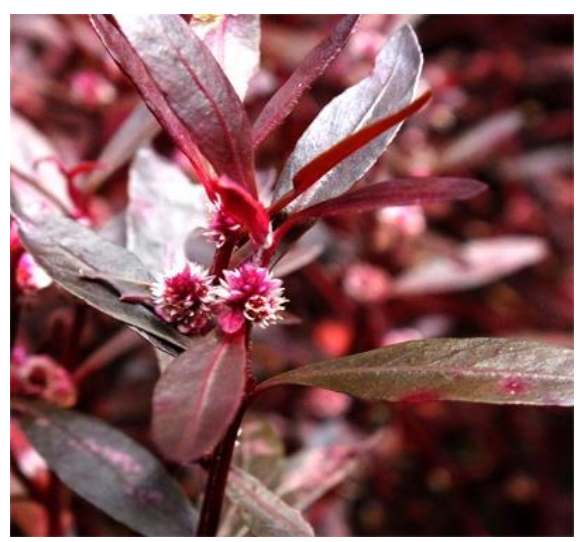

(a)

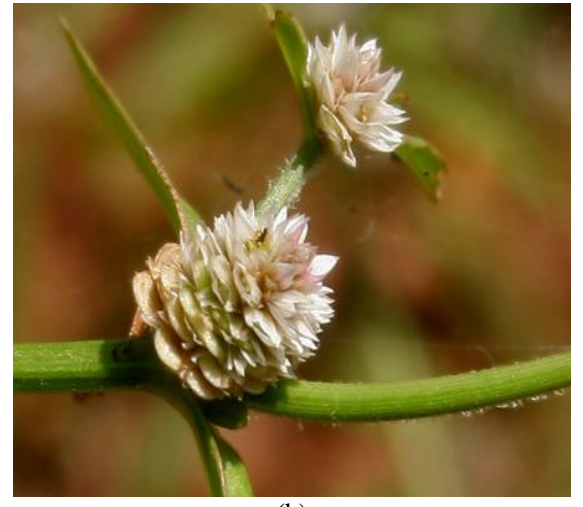

(b)

Fig.1: Alternanthera sessilis: (a) Reddish-purple plant (b) Flower

\section{Sample collection}

The fresh plant which was in good condition was thoroughly washed with water. The leaves were collected and chopped in small pieces and dried in shades on laboratory benches at ambient temperature for one week to ensure it is completely dried. About $1 \mathrm{Kg}$ leaves were pulverized in a grinder for $3 \mathrm{~min}$ and stored in dark bags to protect them from humidity and light prior to analysis.

\section{Isolation of essential oil}

The extraction of essential oil of the dried aerial parts was conducted by hydrodistillation process in a Clevenger-type apparatus for $3 \mathrm{~h}$. The essential oil obtained was then dried over anhydrous sodium sulphate $\left(\mathrm{Na}_{2} \mathrm{SO}_{4}\right)$, filtered and stored in sealed glass vial at $4{ }^{\circ} \mathrm{C}$ in dark, for further analysis.

\section{GC-MS analysis of essential oil}

The samples of A. sessilis red leaves were prepared in methanol and analyzed by injecting into GC-MS branded Perkin Elmer (Model Perkin Elmer Clarus 500, USA) with a split injector at $300{ }^{\circ} \mathrm{C}$. The VF-5 MS fused silica capillary column $(30 \mathrm{~m} \mathrm{x}$ $0.25 \mathrm{mmx} 0.25 \mu \mathrm{m}$ ) was employed. The temperature was adjusted to50 ${ }^{\circ} \mathrm{C}$, held for $10 \mathrm{~min}$, increased at $3{ }^{\circ} \mathrm{C} / \mathrm{min}$ to $250{ }^{\circ} \mathrm{C}$ and finally hold for $10 \mathrm{~min}$. Inert helium gas was employed as a carrier gas at constant flow rate of $1.0 \mathrm{ml} / \mathrm{min}$. The compounds were identified by comparison of their retention indices (RI), with those provided in the National Institute of Standards and Technology (NIST) library. Identification was assumed when a good match of RI was achieved.

\section{DPPH radical scavenging activity}

The antioxidant activity of the extracts was quantitatively assessed on the basis of free radical scavenging activity of stable1, 1-diphenyl-2-picrylhydrazyl (DPPH) radical, according to the method reported by Brand-Williams with slight modifications (Brand-Williams, 1995). $1 \mathrm{ml}$ of plant extracts of various concentrations, ranging between 50 to $200 \mu \mathrm{g} / \mathrm{mlwere}$ mixed with 1 $\mathrm{ml}$ of $0.5 \mathrm{mM}$ DPPH solution in methanol. Incubation,was done for $30 \mathrm{~min}$ in dark at $37^{\circ} \mathrm{C}$. BHT was used as a positive control and negative control was without any inhibitor or plant extract. Absorbance was measured calorimetrically, at $517 \mathrm{~nm}$. The experiments were carried out in triplicate. The percentage inhibition was calculated using the following formula:

$$
\text { DPPH Scavenging Activity }(\%)=[(\text { Ao }- \text { As }) / \text { Ao })] \times 100
$$

Here, Ao is absorbance of the control (no sample, DPPH solution only) and As is absorbance in presence of the sample.

\section{RESULTS}

Hydro-distilled essential oil from fresh flowers and leaves of A.sessilis red were analyzed by GC-MS. The oil was pale yellow with strong aromatic odor. The chemical constituents, retention time and their relative percentage are shown in Table 1 and Table 2. GC-MS analysis of the EO oil of flowers and leaves identified 22 and 18 compounds representing $94.6 \%$ and $98.4 \%$ of the total oil respectively. 
Table 1: Chemical composition of essential oil from leaves of Alternanthera sessilis.

\begin{tabular}{|c|c|c|c|}
\hline Entry & Compound Name & Retention Time & $\%$ Peak area \\
\hline 1 & Methyl propionate & 2.03 & 1.85 \\
\hline 2 & 2,4-Dimethyl-3-pentanol & 2.16 & 1.10 \\
\hline 3 & 2-(1-Methylpropyl)cyclopentanone & 2.24 & 1.01 \\
\hline 4 & 2,3,4-Trimethylpentanoic acid & 2.78 & 0.99 \\
\hline 5 & Methyl-2- $O$-methyl- $\alpha-D$-xylofuranoside & 3.25 & 3.13 \\
\hline 6 & 2,6-Dimethyl-7-octen-3-ol & 4.37 & 0.99 \\
\hline 7 & Tetrahydro-2,5-dimethoxy furan & 4.94 & 10.01 \\
\hline 8 & 9-Heptadecanone & 8.68 & 2.06 \\
\hline 9 & 1-Fluorododecane & 10.09 & 6.60 \\
\hline 10 & 1,1'-Oxybis heptane & 12.61 & 2.41 \\
\hline 11 & 1-Chlorooctadecane & 17.61 & 3.99 \\
\hline 12 & Octyl ester 2-propenoic acid & 23.80 & 9.32 \\
\hline 13 & 2,4,4,6,6,8,8,-Heptamethyl-1-nonene & 25.88 & 1.64 \\
\hline 14 & (Z)-7-tetradecene & 30.79 & 3.12 \\
\hline 15 & 1,1,1,5,5,5-Hexamethyl-3,3-bis[(trimeth-ylsilyl)oxy]trisiloxane & 30.84 & 15.43 \\
\hline 16 & Cis-4-pentyl-5-propyl-2,2-bis(trifluoro methyl)-1,3-dioxolane & 36.05 & 2.29 \\
\hline 17 & 3-Methyl-2-(2-oxopropyl)furan & 36.83 & 1.12 \\
\hline 18 & S,S-Dioxide-trans-2-methyl-4- $N$-pentyl-thiane & 39.03 & 11.27 \\
\hline 19 & Didodecyl phthalate & 42.35 & 10.62 \\
\hline 20 & (S)-Methylester-12-methyl-tetradecanoic acid & 43.03 & 1.13 \\
\hline 21 & Tetracontane-1,40-diol & 45.04 & 1.53 \\
\hline 22 & Trimethyl(4-terbutylphenoxy)silane & 46.10 & 2.98 \\
\hline
\end{tabular}

Table 2: Chemical composition of essential oil from flowers of Alternanthera sessilis.

\begin{tabular}{|c|c|c|c|}
\hline Entry & Compound Name & Retention Time & \% Peak Area \\
\hline 1 & 2-Methyl-1-undecene & 2.02 & 3.50 \\
\hline 2 & Meso-2,5-dimethyl-3,4-hexanediol & 2.15 & 3.43 \\
\hline 3 & 2-(1-Methylpropyl)cyclopentanone & 2.24 & 4.54 \\
\hline 4 & 2,3,4-Trimethylpentanoic acid & 2.77 & 4.17 \\
\hline 5 & Methyl-2- $O$-methyl- $\alpha-D$-xylofuranoside & 3.24 & 2.98 \\
\hline 6 & Tetrahydro-2,5-dimethoxy furan & 4.92 & 9.10 \\
\hline 7 & 2-Ethylhexyl ester-2,2-dimethyl propano-icacid & 6.43 & 5.62 \\
\hline 8 & 1-Fluorododecane & 10.08 & 7.96 \\
\hline 9 & $N$-Dodecylpyridinium chloride & 14.89 & 2.35 \\
\hline 10 & Bis(trimethylsilyl) 4-methyl-4-cyclohex-ene-1,2-dicarboxylic acid & 23.81 & 7.71 \\
\hline 11 & 1,1,1,5,5,5-Hexamethyl-3,3-bis[(trimeth-ylsilyl)oxy] trisiloxane & 30.84 & 17.76 \\
\hline 12 & S,S-Dioxide-2- $N$-propylthiolane & 33.73 & 1.16 \\
\hline 13 & 1R, 2C, 3T, 4T-Tetramethyl cyclohexane & 39.04 & 3.63 \\
\hline 14 & (-)-Cis-3,4-dimethyl-2-phenyltetrahydro-1,4-thiazine & 39.08 & 4.52 \\
\hline 15 & 2-Pentyl-1-heptene & 42.87 & 5.26 \\
\hline 16 & Trimethyl[4-(1,1,3,3,-tetramethylbutyl)- phenoxy]silane & 43.15 & 3.54 \\
\hline 17 & 3-Methyl-2-(2-oxopropyl)furan & 44.36 & 0.09 \\
\hline 18 & Trans-4-ethyl-5-octyl-2,2-bis(triflurome-thyl)-1,3-dioxolane & 45.78 & 11.12 \\
\hline
\end{tabular}

Table 3: Antioxidant activity of Essential oil from Alternanthera sessilis red.

\begin{tabular}{|c|c|c|c|}
\hline & EO of Leaves & EO of Flowers & BHT \\
\hline $\mathrm{DPPH} \mathrm{IC}_{50}(\mu \mathrm{g} / \mathrm{ml})$ & $179 \pm 0.06$ & $170 \pm 0.02$ & $88 \pm 0.04$ \\
\hline
\end{tabular}

The major components of EO of flower based on their peak area were 1,1,1,5,5,5-hexamethyl-3,3bis[trimethylsilyl)oxy]trisiloxane $(17.76 \%)$ which is an oxygenated diterpenes followed by trans-4-ethyl-5-octyl-2,2bis(trifluromethyl)-1,3-dioxolane (11.12\%) and tetrahydro-2,5dimethoxy furan $(9.10 \%)$. The other characteristics compounds determined were 1-fluorododecane $(7.96 \%)$, 2-ethylhexyl ester2,2-dimethylpropanoic acid (5.62\%), bis(trimethylsilyl)-4-methyl4-cyclohexene-1,2-dicarboxylic acid (7.71\%), 2-pentyl-1-heptene (5.26\%), 2-(1-methylpropyl)cyclopentanone (4.54\%), (-)-cis-3,4dimethyl-2-phenyltetrahydro-1,4-thiazine (4.52\%), 1R,2C,3T,4Ttetramethylcyclohexane $(3.63 \%)$ and2-methyl-1-undecene $(3.50 \%)$. However, the major components of EO of leaves, based on their peak area, were 1,1,1,5,5,5-hexamethyl-3,3bis[trimethylsilyl)oxy]trisiloxane (15.43\%) which is an oxygenated diterpenes followed by S,S-dioxide trans-2-methyl-4$N$-pentylthiane (11.27\%), didodecylphthalate (10.62\%) and tetrahydro-2,5-dimethoxy furan (10.01\%). The other characteristics compounds determined were, octyl ester-2propenoic acid (9.32\%), 1-fluorododecane (6.60\%), 1chlorooctadecane $\quad(3.99 \%), \quad$ methyl-2- $O$-methyl- $\alpha-D$ xylofuranoside $(3.13 \%)$, (Z)-7-tetradecene (3.12\%), trimethyl(4terbutylphenoxy)silane (2.98\%), 1,1'-oxybis-heptane $(2.41 \%)$, cis4-pentyl-5-propyl-2,2-bis(trifluoromethyl)-1,3-dioxane $\quad(2.29 \%)$ and 9-heptadecanone $(2.06 \%)$.

From the comparative analysis of scavenging activity of A. sessilis essential oil of flowers $(170 \pm 0.02 \mu \mathrm{g} / \mathrm{ml})$, leaves $(179 \pm 0.06 \mu \mathrm{g} / \mathrm{ml})$ and BHT $(88 \pm 0.04 \mu \mathrm{g} / \mathrm{ml})$, it has been concluded that the essential oil showed moderate activity than that of the synthetic BHT (Table 3). However, analysis showed that the 
radical scavenging activity of essential oil increases with the increase in concentration (Fig. 2).

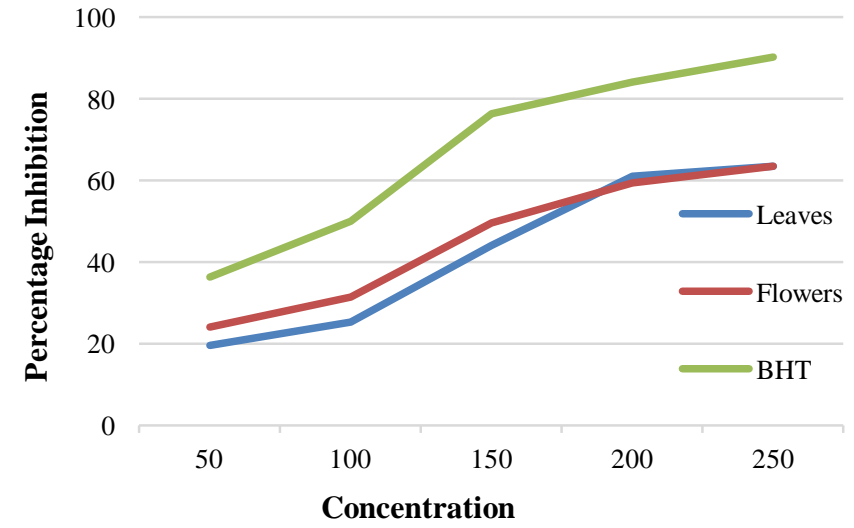

Fig 2: DPPH scavenging activity of essential oil of flowers and leaves of Alternanthera sessilis.

\section{DISCUSSION}

Among the detected compounds most of the compounds were found to be quite good therapeutic agents. For instance, the didodecylphthalate $(10.62 \%)$ possesses antioxidant and antibacterial activities (Kalaiarasan, 2012; Sujatha et al., 2015).The analysis of essential oil showed the presence of oxygenated sesquiterpenes, diterpenes, ketones, fatty acid and esters. These different phytochemicals have been reported to have antioxidant, anti-inflammatory and immune modulating activities (Tacouri et al., 2013; Silveria et al., 2013; Prakasia and Nair, 2015). Terpenes have promising biological activities which protect human cell from oxidative stress due to free radicals (Zengin and Baysal, 2014). It has been proved that the accumulated toxins from liver and kidney can be reduced by the intake of proper dose of terpene which contains antioxidants (Soares et al., 2013; Karau et al., 2015). In addition, sesquiterpenes are also used in pharmaceuticals which are highly effective against inflammatory and allergic infections (Meyers et al., 2013). The reported antioxidant activity of the essential oil from flower and leaves is expected due to the presence of different terpenes and fatty acids. Methyl esters were proven to show antioxidant activities. S,Sdioxide-2- $N$-propylthiolane compounds with different alkyl chains have been reported to show antioxidant activities. 1Fluorododecane also reported to show antibacterial activity (Siddiqui, 2014). Compounds having suffixes 'siloxanes' belongs to the class of organo-silicon compounds. The chemical constituents of siloxanes comprises of organic as well as inorganic compounds which includes silicon, oxygen, carbon and hydrogen. Cosmetic industries predominantly use siloxanes, to produce sunblocks, deodorant, hairspray and skincare (Omoruyi et al., 2014). There were seven compounds which have been found to be present in the essential oil of leaves and flowers, indicating that these are evenly distributed throughout the plant. These compounds are,2-(1-methylpropyl)-cyclopentanone, 2,3,4trimethylpentanoic acid, methyl 2-O-methyl- $\alpha-D$-xylofuranoside, tetrahydro-2,5-dimethoxy furan, 1-fluorododecane, 1,1,1,5,5,5hexamethyl-3,3-bis[(trimethylsilyl)oxy]trisiloxane, and 3-methyl2-(2-oxopropyl)furan.

The antioxidant effect on DPPH radical scavenging capacities was conceived to their hydrogen donating ability (Abed et al., 2014). The principle is based on availability of electron or hydrogen radicals to neutralize the DPPH free radical to become a stable diamagnetic molecule. The degree of decolorization indicates the scavenging potential of compounds in short time. The free radial scavenging activity of essential oil on DPPH may be due their hydrogen donating ability which reduces the stable DPPH free radical violet colour to pale yellow DPPH-H. The results of antiradical activities of essential oil from flower and leaves were usually represented by $\mathrm{IC}_{50}$ value. $\mathrm{IC}_{50}$ value is the concentration of effective sample needed to scavenge $50 \%$ of DPPH present in the sample solution.

\section{CONCLUSION}

The analysis of essential oil showed the presence of oxygenated sesquiterpenes, diterpenes, ketones, fatty acid and esters. These result suggested that the essential oil of $A$. sessilis red exhibits moderate antioxidant property. The scavenging activity of A. sessilis essential oil of flowers and leaves were found to be $170 \pm 0.02 \mu \mathrm{g} / \mathrm{ml}$ and $179 \pm 0.06 \mu \mathrm{g} / \mathrm{ml}$ respectively as compared to BHT $(88 \pm 0.04 \mu \mathrm{g} / \mathrm{ml})$.

\section{ACKNOWLEDGMENT}

The authors thank Faculty of Science and Natural Resources, Universiti Malaysia Sabah for providing necessary research facilities. The authors express sincere gratitude to The Institute of Biotechnology, Universiti Malaysia Sabah to support the research.

Financial support and sponsorship: Thanks are due to Malaysian Government and UMS for the providing the grant SLB0052-SG-2013 to conduct this work.

Conflict of Interests: There are no conflicts of interest.

\section{REFERENCES}

Brand-Williams W, Cuvelier ME, Berset CL. Use of a free radical method to evaluate antioxidant activity. Food Sci Technol, 1995; 28(1):25-30.

Das D, Borua PK. In vitro Propagation of Alternanthera sessilis L. from internode explant. Br Biotechnol J, 2014; 4(1):74-80.

Das M, Kumar AD, Mastanaiah K, Das A.Evaluation of antidiabetic activity of ethanolic extract of Alternanthera sessilis Linn. in streptozotocin-induced diabetic rats. Int J Pharma Sci Res, 2015; 7(6):1027-1032.

Nariman EA, KaabiB,Samaali MI, Chabbouh M, Habibi K, Mejri M, Marzouki MN, Ahmed SBH. Chemical composition, antioxidant and antimicrobial activities of Thymus capitate essential oil with its preservative effect against Listeria monocytogenesinoculated in minced beef meat. [ONLINE] Available at: http://dx.doi.org/10.1155/2014/283938. [Accessed 11 April 2016].

Hossain MA, Shah MD. A study on the total phenols content and antioxidant activity of essential oil and different solvent extracts of endemic plant Merremiaborneensis. Arab J Chem, 2015; 8(1):66-71. 
KalaiarasanA, Kumar P, Ahmed SJ. Biochemical investigation of BulbophyllumkaitenseRechib. root by GC-MS: Esternghats of India. Nat Sci, 2012; 10(2):29-31.

KarauGM, Njagi EN, Machocho, AK, Wangai LN, Nthinga MJ. Chemical composition and in vitro antioxidant activities of Ocimumamericanum. Adv AnalChem, 2015;5(2):42-49.

Meyers VE, Garcia HD, McMullin TS, Tobin JM, James JT. Safe human exposure limits for airborne linear siloxanes during spaceflight. InhalToxicol, 2013;25(13):735-46.

Nayak P, Nayak S, Kar DM. Pharmacological evaluation of ethanolic extracts of the plant Alternanthera sessilis against temperature regulation. J Pharm Res, 2010; 3(6):1381-1383.

Nimse SB, Pal D. Free radicals, natural antioxidants, and their reaction mechanisms. R SocChemAdv, 2015; 5:27986-28006.

Omoruyi BE, Afolayan AJ, Bradley G. The inhibitory effect of Mesembryanthemumedule (L.) bolus essential oil on some pathogenic fungal isolates. BMC ComplAltern Med, 2014; 14: 168-175.

Patel SD, ShahS, Shah N. A review on herbal drugs acting against Acne Vulgaris. J Pharm Sci Bio-Sci Res, 2015;2(5):165-171.

Prakasia PP, Nair AS. Chemical fingerprint of essential oil components from fresh leaves of Glycosmispentaphylla (Retz.) Correa. The Pharm Innov J, 2015; 3(12):50-56.

Quattrocchi U. 2012. CRC World Dictionary of Medicinal and Poisonous Plants: Common Names, Scientific Names, Eponyms, Synonyms, and Etymology. 5 Vol set: Boka Raton, USA: CRC Press.

Siddiqui NA. Chemical constituents of essential oil from flowers of Matricariaaurea grown in Saudi Arabia. Indian J Drugs, 2014;2(4):164-168.

Silveria RC, Andrade LN, Sausa DP. A review on antiinflammatory activity of monoterpenes. Molecules, 2013;18(1):12271254.

Soares AA, de Sa-Nakanishi AB, Bracht A, da Costa SM, Koehnlein EA, de Souza CG, Peralta RM.Hepatoprotective effects of mushrooms. Molecules, 2013; 18(7):7609-7630.
Sujatha, Karthika, Sivakamasundari, Mariajancyrani, Chandramohan. GC-MS analysis of phytocomponents and total antioxidant activity of hexane extract of Sinapis alba.Int J Pharm ChemBiolSci, 2014; 4(1):112-117.

Tacouri DD, Ramful-Baboolall D, Puchooa D.In vitro bioactivity and phytochemical screening of selected spices used in Mauritian foods. Asian Pac J Trop Dis, 2013; 3(4):253-261.

Tan KK, Kim KH. Alternanthera sessilis Red ethyl acetate fraction exhibits antidiabetic potential on obese type 2 diabetic rats. Evid Based ComplemAltern Med, 2013;1-9.

Vennila V, Nivetha R. Screening the in-vitro anthelmintic activity of Alternanthera sessilis leaves. World J Pharm PharmSci, 2015; 4(4):1402-1415.

Vinodh KSL, Kumar BS.GC-MS analysis of aqueous leaf extract ofAlternanterasessilis. Int J Pharm ResSch, 2014; 3(1):382-387.

Zengin $\mathrm{H}$, Baysal AH. Antibacterial and antioxidant activity of essential oil terpenes against pathogenic and spoilage-forming bacteria and cell structure-activity relationships evaluated by SEM microscopy. Molecules, 2014;19(11):17773-17798.

\section{How to cite this article:}

Khan MS, Yusufzai SK, Kaun LP, Shah MD, Idris R. Chemical composition and antioxidant activity of essential oil of leaves and flowers of Alternanthera sessilis red from Sabah. J App Pharm Sci, 2016; 6 (12): 157-161. 